Pesq. Vet. Bras. 28(1):57-62, janeiro 2008

\title{
Intoxicação experimental por Sida carpinifolia (Malvaceae) em bovinos ${ }^{1}$
}

\author{
Fernando H. Furlan², Joelma Lucioli², Luciane O. Veronezi ${ }^{3}$, \\ Sandra D. Traverso ${ }^{2}$ e Aldo Gava ${ }^{2 *}$
}

\begin{abstract}
Furlan F.H., Lucioli J., Veronezi L.O., Traverso S. D. \& Gava A. 2008. [Experimental poisoning by Sida carpinifolia (Malvaceae) in cattle.] Intoxicação experimental por Sida carpinifolia (Malvaceae) em bovinos. Pesquisa Veterinária Brasileira 28(1):57-62. Departamento de Clínica e Patologia, Centro de Ciências Agroveterinárias, Universidade do Estado de Santa Catarina, Lages, SC 88520-000, Brazil. E-mail: a2ag@cav.udesc.br

Clinical and pathological findings of experimental poisoning by Sida carpinifolia in cattle are described. A neurologic disease was observed in cattle on farms of the Alto Vale do Itajaí region of the Brazilian state of Santa Catarina. For the experimental reproduction of the disease, fresh green leaves, weekly harvested in the same region where spontaneous case occurred, were force-fed to five cattle at doses of 10 and $20 \mathrm{~g} /$ $\mathrm{kg}$ for 120 days, $40 \mathrm{~g} / \mathrm{kg}$ for 30 days, and 30 and $40 \mathrm{~g} / \mathrm{kg}$ body weight for 150 days. One animal died and the others were euthanatized at the end of the experiment. Clinical signs and lesions varied from mild to severe in the experimentally poisoned cattle and depended on dose and length of the period of consumption. Main histological and ultrastructural lesions consisted of vacuolation and distension of neuronal perikarya (mainly of Purkinje cells), and of the cytoplasm of acinar pancreatic cells and thyroid follicular cells. It is concluded that ingestion of even small amounts $S$. carpinifolia for prolonged periods of time cause lisosomal storage disease in cattle.
\end{abstract}

INDEX TERMS: Poisonous plants, Sida carpinifolia, Malvaceae, cattle, storage disease, alphamannosidosis.

RESUMO.- Descrevem-se os achados clínicos e patológicos da intoxicação experimental por Sida carpinifolia em bovinos. Para a reprodução experimental da doença, foIhas verdes da planta foram coletadas semanalmente na região do Alto Vale do Itajaí e fornecidas in natura diariamente para cinco bovinos nas doses de 10 e $20 \mathrm{~g} / \mathrm{kg}$ por 120 dias, $40 \mathrm{~g} / \mathrm{kg}$ por 30 dias, e 30 e $40 \mathrm{~g} / \mathrm{kg}$ de peso ani-

\footnotetext{
${ }^{1}$ Recebido em 4 de outubro de 2007.

Aceito para publicação em 25 de outubro de 2007.

Parte experimental da Dissertação de Mestradodo primeiro autor, defendida no Centro de Ciências Agroveterinárias (CAV), Universidade do Estado de Santa Catarina (UDESC), Lages, SC.

2 Laboratório de Patologia Animal, Departamento de Clínica e Patologia, CAV, UDESC, Avenida Luiz de Camões 2090, Bairro Conta Dinheiro, Lages, SC 88520-000, Brasil. *Autor para correspondência: a2ag@cav.udesc.br

${ }^{3}$ Programa de Pós-Graduação em Ciências Veterinárias, área de concentração em Patologia Veterinária, CAV, UDESC, Lages, SC.
}

mal por 150 dias. Um bovino morreu e os outros foram eutanasiados ao final do período de consumo da planta. Os principais sinais clínicos consistiam de andar em marcha, olhar atento e tremores de cabeça e foram de intensidade leve a acentuado conforme a dose de planta e tempo de consumo. A lesão histológica predominante caracterizava-se por vacuolização e tumefação de neurônios (principalmente os de Purkinje), das células acinares pancreáticas e células foliculares da tireóide. Ultra-estruturalmente verificou-se vacúolos, por vezes, contendo material finamente granular em neurônios, células acinares pancreáticas e células foliculares da tireóide. S. carpinifolia causa doença de depósito lisossomal em bovinos quando consumida por período prolongado, mesmo em pequenas doses.

TERMOS DE INDEXAÇÃO: Plantas tóxicas, Sida carpinifolia, Malvaceae, bovino, doença de armazenamento, alfa-manosidose. 


\section{INTRODUÇÃO}

Uma doença de caráter crônico, caracterizada por tremores de cabeça e pescoço, olhar atento, andar cambaleante e subdesenvolvimento ocorre em bovinos no Alto Vale do Itajaí, Santa Catarina, e é atribuída ao consumo de Sida carpinifolia (Furlan et al 2005, Furlan 2007). Essa enfermidade ocorre somente em bovinos que pastoreiam em piquetes com grande quantidade de $S$. carpinifolia (guanxuma, mata-pasto). A intoxicação por esta planta ja foi descrita em caprinos (Driemeier et al. 2000, Colodel et al. 2002a, Godoy et al. 2005), ovinos (Seitz et al. 2005), eqüinos (Loretti et al. 2003a) e bovinos (Furlan et al. 2005, Furlan 2007) e caracteriza-se por por incoordenação motora, ataxia com dismetria e tremores de cabeça associados a quedas freqüentes. Em pôneis o quadro clínico inclui andar rígido, tremores musculares generalizados, chutes no flanco, rolamento, quedas e gemidos, seguidos de recumbência e morte. À necropsia não são observadas lesões. Microscopicamente as lesões mais significativas são caracterizadas por vacuolização citoplasmática de neurônios (principalmente os de Purkinje), células acinares do pâncreas e células foliculares da tireóide (Driemeier et al. 2000, Colodel et al. 2002a, Loretti et al. 2003a, Godoy et al. 2005, Colodel 2005, Seitz et al. 2005, Furlan et al. 2005, Furlan, 2007).

S. carpinifolia, da família Malvaceae, é uma planta daninha bastante freqüente em locais úmidos e sombreados, invadindo principalmente pastagens e terrenos baldios (Lorenzi 2000). Dessa planta foi isolado o alcalóide swainsonina (Colodel et al. 2002b) que inibe as enzimas alfa-manosidase lisossômica (Dorling et al. 1980) e alfamanosidase II do complexo de Golgi (Tulsiani et al. 1982). A inibição dessas enzimas, principalmente da alfamanosidase lisossômica, causa uma doença de depósito lisossomal (DDL) caracterizada pelo acúmulo de oligossacarídeos não totalmente hidrolisados nos lisossomos (Dorling et al. 1978). DDL associada ao consumo deste princípio ativo é verificada também na intoxicação por Astragalus spp. e Oxytropis spp. (locoweeds), nos Estados Unidos (James et al. 1981), Swainsona spp., na Austrália (Laws \& Anson 1968) e Ipomoea sp., no Sudão (Damir et al. 1987), Moçambique (Balogh et al. 1999) e Argentina (Armesto et al. 2004). No Brasil DDLs associadas à swainsonina têm sido verificadas na intoxicação por Ipomoea sericophylla, I. riedelii (Barbosa et al. 2006), I. carnea (Armién et al. 2007) e Turbina cordata (Dantas et al. 2006

O presente trabalho tem por objetivo caracterizar os sinais clínicos, lesões macroscópicas, microscópicas e ultraestruturais da intoxicação experimental por $S$. carpinifolia em bovinos e confirmar que o consumo desta planta é a causa da doença que ocorre na região do Alto Vale do Itajaí, SC.

\section{MATERIAL E MÉTODOS}

Para o estudo experimental, foram utilizados cinco bovinos machos das raças holandês e Jersey, oriundos de propriedade livre de Sida carpinifolia (fam. Malvaceae), os quais foram

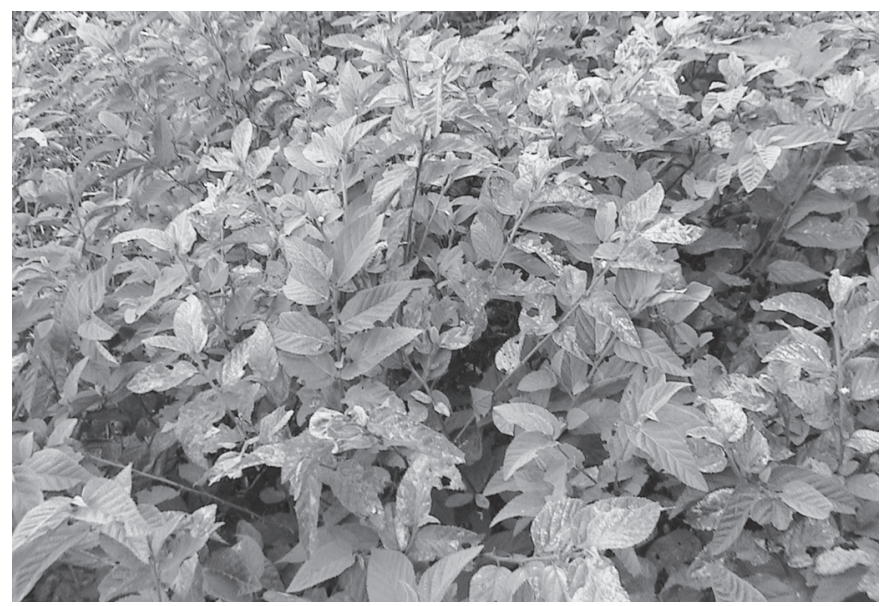

Fig.1. Sida carpinifolia. Município de José Boiteux, Santa Catarina.

mantidos, durante a noite, em baias individuais e durante o dia em piquete formado por capim quicuio (Pennisetum clandestinum). As folhas verdes de S. carpinifolia (Fig.1) foram coletadas semanalmente na região do Alto Vale do Itajaí, nos municípios de José Boiteux, Vitor Meireles, Witmarsum e Rio do Sul, foram conservadas em câmera fria e fornecidas, in natura, no cocho, diariamente aos animais. O delineamento do experimento está ilustrado no Quadro 1.

O experimento foi conduzido em duas etapas. Para a

\section{Quadro 1. Delineamento do experimento com Sida carpinifolia verde em bovinos}

\begin{tabular}{cccc} 
Bovinono. & Idade (meses) & Dose $(\mathrm{g} / \mathrm{kg} / \mathrm{dia})$ & Tempo (dias) \\
\hline 1 & 24 & 10 & 120 \\
2 & 18 & 20 & 120 \\
3 & 16 & 40 & 30 \\
4 & 24 & 30 & 150 \\
5 & 18 & 40 & 150
\end{tabular}

primeira etapa (Bovinos 1, 2 e 3) a planta foi coletada no período de outubro a dezembro de 2005 e para a segunda etapa (Bovinos 4 e 5) no período de fevereiro a julho de 2006. Durante o período de experimentação, os bovinos eram observados diariamente, com avaliação do comportamento, temperatura corporal, movimentos ruminais, freqüência respiratória e cardíaca, movimentação espontânea e induzida, consistência das fezes, coloração das mucosas e realização do HR test (head raising test) que consiste em levantar a cabeça do animal dorso caudalmente ao tronco e soltá-la após 60 segundos, sendo considerado positivo quando o animal apresenta sinais neurológicos (Pienaar et al. 1976). No final do período experimental todos os animais, exceto o Bovino 3, foram eutanasiados para necropsia. Para microscopia óptica amostras de SNC, medula espinhal, gânglio trigeminal, língua, glândula salivar, rúmen, retículo, omaso, abomaso, intestino delgado, intestino grosso, pulmão, coração, pâncreas, tireóide, adrenal, baço, linfonodos, fígado, rim, musculatura esquelética, medula óssea e testículos foram fixadas em formalina tamponada $10 \%$, desidratadas em álcool, clarificadas em xilol e incluídas em parafina. Secções de cinco micrômetros de espessura foram coradas pela técnica de hematoxilina e eosina (HE). No sistema nervoso central foram estudadas cortes transversais de cinco 
regiões: córtex cerebral rostralmente ao quiasma óptico, córtex cerebral e tálamo caudal ao corpo mamilar, mesencéfalo sobre a fossa interpeduncular, cerebelo e ponte sobre o pedúnculo cerebelar e região do óbex (Colodel 2005). Fragmentos do cerebelo, pâncreas e tireóide dos Bovinos 1 e 2 foram coletados para microscopia eletrônica em glutaraldeído $2 \%$ tamponado em cacodilato de sódio, refixadas em tetróxido de ósmio a $1 \%$, desidratadas em soluções crescentes de etanol e incluídas em Epon. Os cortes ultrafinos foram contrastados com acetato de uranila e citrato de chumbo.

\section{RESULTADOS}

\section{Aspectos clínicos}

Os animais desenvolveram, ao final da primeira semana de experimento apetite pela planta e passaram a consumi-la mesmo logo após retornarem do período de pastejo. Todos os animais apresentaram alteração na consistência das fezes caracterizada por fezes pastosas, raramente líquidas com apresentação em períodos intermitentes e curso clínico de 24-48 horas. Excepcionalmente, os Bovinos 4 e 5 apresentaram no final do primeiro mês de experimentação fezes escassas e com muco. Com exceção do Bovino1, todos os outros animais não tiveram ganho de peso ou apresentaram emagrecimento (Quadro 2).

Alterações clínicas foram observadas a partir da primeira semana de experimento no Bovino 3 , da quarta semana no Bovino 2 e da sexta semana no Bovino 1. Essas alterações foram de intensidade leve e consistiam em olhar atento com orelhas voltadas para trás, movimentação lenta, andar em "marcha" com passos curtos e pescoço esticado para frente e para baixo. Além desses sinais havia ainda distúrbios de propriocepção, andar cambaleante e às vezes tropeções. Os animais apresentavam também hiperexcitação e assustavam-se facilmente

\section{Quadro 2. Variação de peso médio/dia de bovinos experi- mentalmente intoxicados com Sida carpinifolia}

\begin{tabular}{cccccc}
\hline Bovino & $\begin{array}{c}\text { Dose } \\
\text { diária } \\
(\mathrm{g} / \mathrm{kg})\end{array}$ & $\begin{array}{c}\text { Período } \\
(\text { dias })\end{array}$ & $\begin{array}{c}\text { Peso inicial } \\
(\mathrm{kg})\end{array}$ & $\begin{array}{c}\text { Peso final } \\
(\mathrm{kg})\end{array}$ & $\begin{array}{c}\text { Variação de peso } \\
\text { médio/dia }(\mathrm{g})\end{array}$ \\
\hline 1 & 10 & 120 & 269 & 300 & 250 \\
2 & 20 & 120 & 250 & 250 & 0 \\
3 & 40 & 30 & 101 & 100 & 0 \\
4 & 30 & 150 & 221 & 200 & -140 \\
5 & 40 & 150 & 145 & 135 & -60
\end{tabular}

Quadro 3. Tempo de consumo de planta para início das alterações neurológicas e intensidade dos sinais clínicos relacionados à dose diária de planta em bovinos experimentalmente intoxicados com Sida carpinifolia

\begin{tabular}{cccccc}
\hline $\begin{array}{c}\text { Bovino } \\
\text { no. }\end{array}$ & $\begin{array}{c}\text { Dias con- } \\
\text { sumo }\end{array}$ & $\begin{array}{c}\text { Dose } \\
(\mathrm{g} / \mathrm{kg})\end{array}$ & \multicolumn{3}{c}{ Início dos sinais neurológicos (dias) } \\
\cline { 5 - 6 } \cline { 5 - 6 } & 120 & 10 & 41 & - & - \\
2 & 120 & 20 & 27 & - & - \\
3 & 30 & 40 & 7 & - & - \\
4 & 150 & 30 & 58 & 99 & - \\
5 & 150 & 40 & 55 & 77 & 150
\end{tabular}

com qualquer barulho ou toque e tinham medo de sair da baia ou passar por canaletas. Os sinais clínicos considerados moderados foram observados apenas nos bovinos $4(30 \mathrm{~g} / \mathrm{kg})$ e $5(40 \mathrm{~g} / \mathrm{kg})$ a partir do $99^{\circ}$ e $77^{\circ}$ dias de experimentação, respectivamente, e consistiam de aumento dos cambaleios, com tropeções mais freqüentes e, às vezes, quedas. Havia dificuldades de transpor obstáculos como subir e descer calçadas. Quando submetidos à movimentação, às vezes, apresentavam tremores leves de cabeça e pescoço. O Bovino 5 apresentou, a partir do $150^{\circ}$ dia, sinais clínicos severos caracterizados por tropeções e quedas freqüentes, incoordenação motora com andar cambaleante e hipermetria, além de tremores constantes de cabeça e pescoço. Submetidos ao HR test e quando movimentados, os animais tinham os sinais clínicos exacerbados e o Bovino 5 ao final do período de experimentação apresentava quedas quando submetido a esse teste. O Bovino 3 foi encontrado morto, sem causa aparente, ao $30^{\circ}$ dia após o início do experimento. Os sinais clínicos variaram entre os animais de acordo com o período de consumo da planta e da dose diária consumida. Esses dados estão resumidos no Quadro 3.

\section{Achados de necropsia, microscopia óptica e eletrônica}

À necropsia não foram observadas alterações macroscópicas em nenhum dos animais. Através da microscopia óptica, nos Bovinos 1 e 3 foi observado, no cerebelo, vacuolização leve de neurônios de Purkinje e nos neurônios da camada de células granulares. Na camada molecular verificaram-se vacúolos, às vezes com conteúdo finamente granular (Fig.2). Vacuolização leve a moderada foi observada nas células acinares pancreáticas e células foliculares da tireóide. Adicionalmente, no bovino 1 havia esferóides axonais, principalmente na região do óbex, gliose focal no córtex do encéfalo e bulbo além de infiltrado mononuclear leve ao redor de vasos do cortex encefálico e na piamáter. O Bovino 2 apresentou lesões semelhantes aos Bovinos 1 e 3 , porém de intensidade

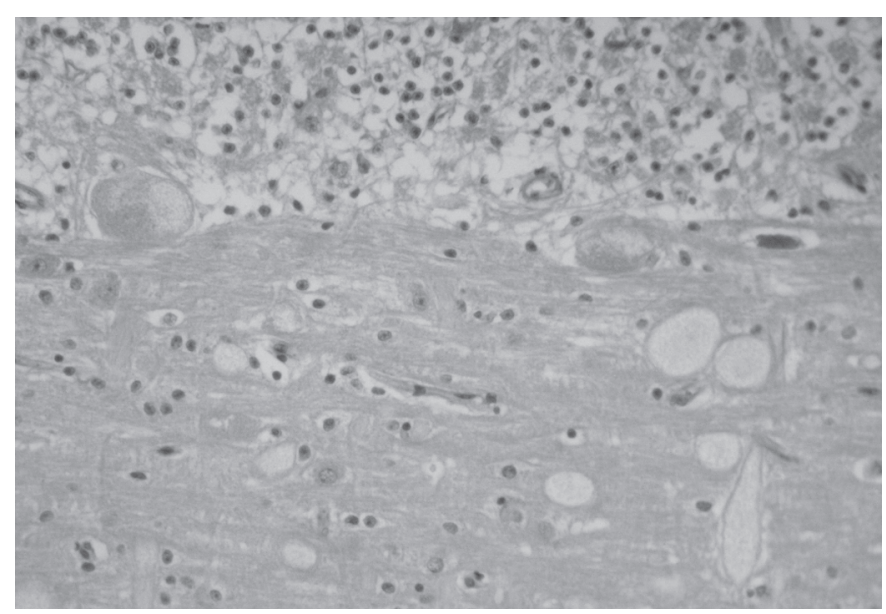

Fig.2. Vacuolização em neurônios de Purkinje e vacúolos com conteúdo finamente granular na camada molecular do cerebelo (Bovino 1). HE, obj.20x. 

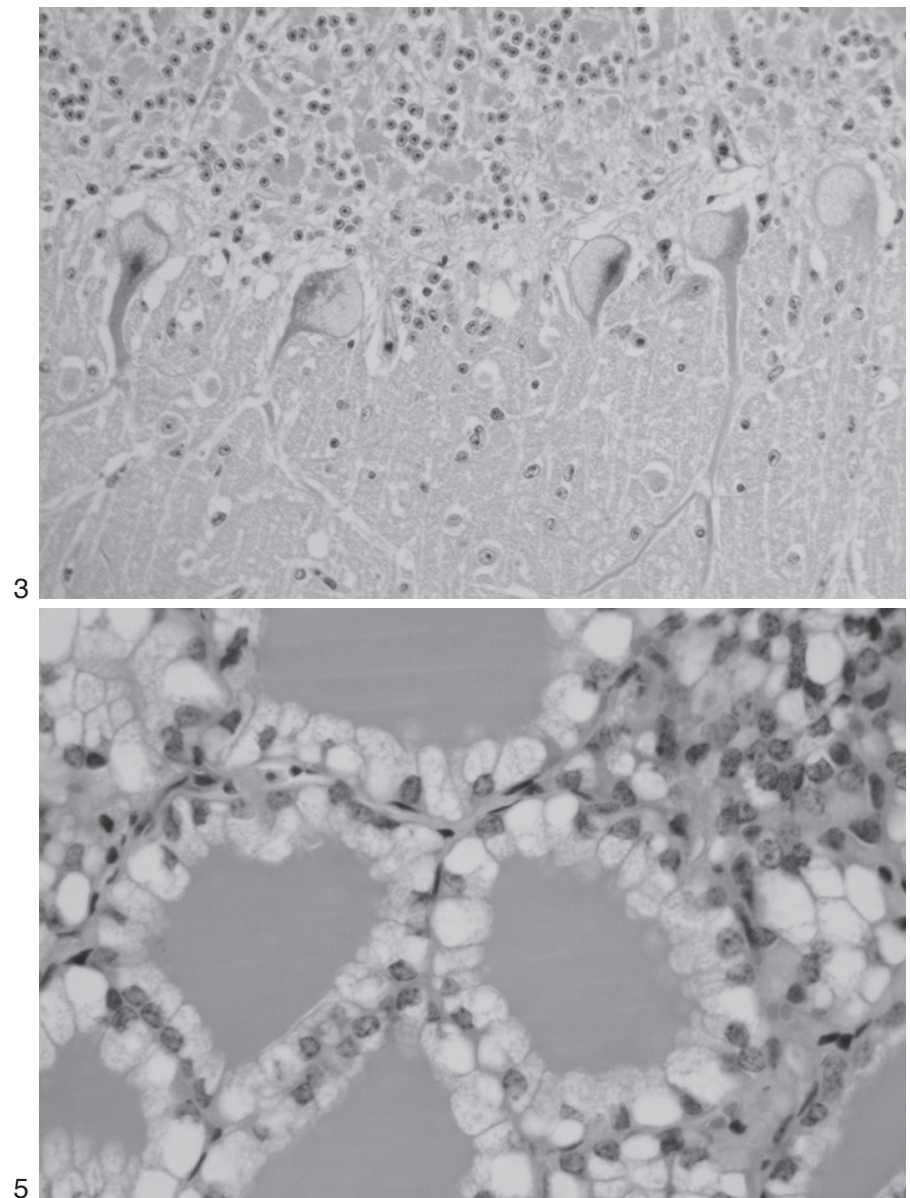

Fig.3. Vacuolização difusa em neurônios de Purkinje (Bovino 4). HE, obj.20x.

Fig.5. Vacuolização em céulas foliculares da tireóide (Bovino 5). HE, obj.40x.

moderada. Em algumas áreas notava-se rarefação de neurônios de Purkinje e proliferação de células gliais de Bergman, bem como, áreas com grupos de neurônios encarquilhados. Vacuolização leve foi observada também em neurônios do gânglio trigeminal e da medula espinhal e células foliculares da tireóide. Nos Bovinos 4 e 5 as lesões eram mais acentuadas e difusas. Também havia vacuolização em neurônios (Fig.3) e esferóides no bulbo e vacuolização em neurônios da medula espinhal. Adicionalmente, no Bovino 5, observou-se vacuolização moderada a acentuada em células acinares do pâncreas (Fig.4), células foliculares da tireóide (Fig.5) e células epiteliais do epidídimo. No pericário de neurônios de Purkinje e no citoplasma de células foliculares da tireóide verificou-se ultra-estruturalmente, nos Bovinos 1 e 2, vacúolos delimitados por membranas, por vezes com conteúdo finamente granular (Fig.6). Adicionalmente no citoplasma das células foliculares da tireóide havia grânulos de secreção eletrodensos.

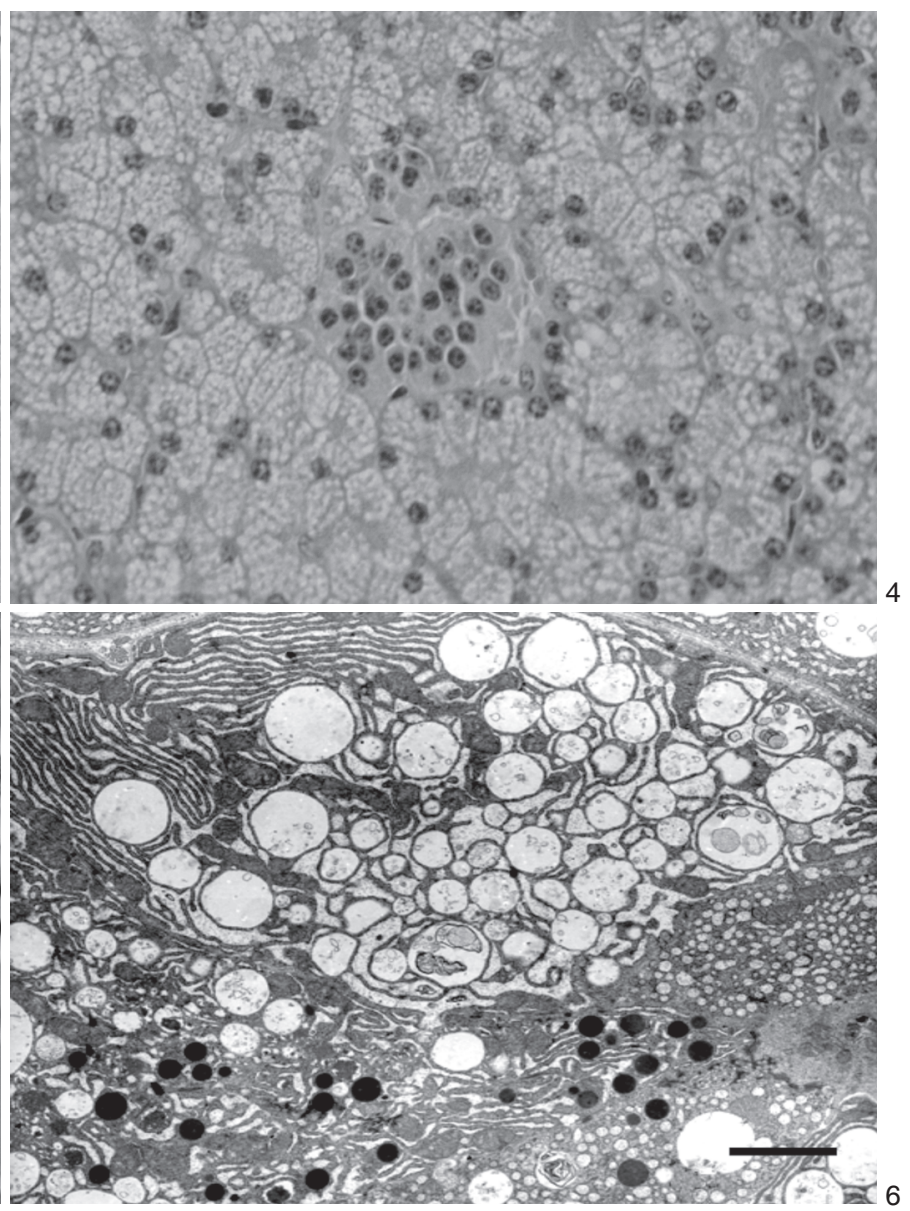

Fig.4. Vacuolização em células acinares pancreáticas (Bovino 4). HE, obj.40x.

Fig.6. Citoplasma de célula folicular da tireóide com grânulos de secreção eletrodensos (setas) e vacúolos delimitados por membranas contendo material finamente granular (cabeças de setas), (Bovino 2). Barra: $3 \mu \mathrm{m}$.

\section{DISCUSSÃO}

Os principais sinais clínicos observados em bovinos intoxicados experimentalmente por Sida carpinifolia foram alterações neurológicas caracterizadas principalmente por incoordenação motora, dismetria, tremores de cabeça e pescoço, desequilíbrio e dificuldade em levantar-se. Estes sinais são semelhantes aos descritos na intoxicação espontânea por S. carpinifolia em bovinos (Furlan et al 2005) e espontânea e experimental em ovinos e caprinos (Driemeier et al. 2000, Colodel et al. 2002a, Colodel 2005, Seitz et al. 2005). Diarréia foi observada nos primeiros dias de consumo de S. carpinifolia. Colodel (2005) faz referência a proprietários que mencionaram a ocorrência de diarréia em bovinos logo nos primeiros dias após os animais serem colocados em piquetes invadidos por $S$. carpinifolia. Essas alterações foram verificadas também em caprinos e ovinos experimentalmente intoxicados por essa planta (Colodel 2005, Seitz et al. 2005). Perda de peso em bovinos, ovinos e eqüinos tem sido relatada na 
intoxicação por locoweeds (James et al. 1981) e por S. carpinifolia em caprinos (Driemeier et al. 2000, Colodel et al. 2002a, Colodel 2005) e bovinos (Furlan et al. 2005, Furlan 2007). Na reprodução experimental da doença houve perda de peso em três bovinos e em dois não houve ganho de peso.

As principais alterações neurológicas observadas na doença experimental refletiam principalmente as alterações cerebelares. Essas alterações foram relacionadas com a intensidade dos sinais clínicos, com o tempo de consumo e quantidade de $S$. carpinifolia ingerida, bem como, com a intensidade da vacuolização e distensão do citoplasma, principalmente dos neurônios de Purkinje. Vacuolização finamente granular difusa, conferindo ao citoplasma um aspecto espumoso, associada ou não à tumefação celular, verificada principalmente em neurônios, células acinares pancreáticas e células foliculares da tireóide, foi o achado microscópico mais significativo. Essas alterações também foram descritas na intoxicação espontânea em bovinos (Furlan et al. 2005, Furlan 2007) e na intoxicação espontânea e/ou experimental em caprinos (Driemeier et al. 2000, Colodel et al. 2002a, Colodel 2005), ovinos (Seitz et al. 2005) e pôneis (Loretti et al. 2003a). Lesões semelhantes são descritas também em casos de intoxicações por outras plantas que contém o alcalóide swainsonina (Dorling et al. 1978, James et al. 1981, Balogh et al. 1999, Barbosa et al. 2006, Dantas et al. 2006), em casos de alfa-manosidose hereditária bovina (Whittem \& Walker 1957, Jolly \& Thompson 1978), humana (Ockerman 1967), de felinos domésticos (Burditt et al. 1980, Maenhout et a. 1988) e de cobaios (Muntz et al. 1999). Na alfa-manosidose adquirida, o alcalóide swainsonina inibe a alfa manosidase lisossômica (Dorling et al. 1980, Elbein et al. 1981, Chotai et al. 1983), o que resulta em acúmulo e excreção de oligossacarídeos parcialmente degradados, assim como ocorre na forma hereditária da doença, porém swainsonina inibe também a alfa manosidade II do aparelho de Golgi modificando a síntese de glicoproteínas (Tulsiani et al. 1982, Tulsiani \& Touster 1983). Dessa forma, a atividade enzimática e excreção de oligossacarídeos diferem entre a doença adquirida e hereditária (Fuhrmann et al. 1985). Neurônios encarquilhados caracterizados por núcleos picnóticos com citoplasma eosinofílico e bordos citoplasmáticos irregulares foram achados freqüentes nos bovinos que estavam gravemente doentes. Essas observações foram verificadas também na intoxicação por $S$. carpinifolia em caprinos (Driemeier et al. 2000, Colodel et al. 2002a, Colodel 2005) e ovinos (Seitz et al. 2005). Os vacúolos contendo material finamente granular verificados na camada molecular do cerebelo de bovinos experimentalmente intoxicados por S. carpinifolia podem ser atribuídos à formação de vacúolos em axônios de neurônios com vacuolização acentuada ou encarquilhados.

As alterações ultra-estruturais observadas na intoxicação por S. carpinifolia em bovinos foram semelhantes às citadas por Driemeier et al. (2000) para caprinos e Seitz et al. (2005), para ovinos. Na maioria das vezes os lisossomas estavam vazios, por vezes com conteúdo finamente granular. Os vacúolos de depósito lisossomal estão geralmente vazios na alfa manosidose devido à solubilidade do material depositado que geralmente se dilui durante o processamento das amostras (Jolly \& Thompson 1978, Summers et al. 1994).

Para intoxicação por S. carpinifolia é necessário fazer o diagnóstico diferencial de intoxicação por outras plantas que cursam com sinais clínicos nervosos. Atenção especial dever ser dada às doenças nervosas que têm apresentação clínica tremogênica e/ou causam vacuolização neuronal. Além da caracterização dos sinais clínicos e das lesões microscópicas, torna-se necessário a obtenção dos dados epidemiológicos e a presença da planta no local. A intoxicação por Turbina cordata, Ipomoea carnea, I. sericophylla e I. riedelii afetam principalmente caprinos e ovinos e ocorrem com maior freqüência no nordeste (Tokarnia et al. 2000, Barbosa et al. 2006, Dantas et al. 2006, Barros et al. 2006), porém recentemente reconheceu-se um surto de intoxicação por $I$. carnea em bovinos no Estado do Mato Grosso (Edson Moleta Colodel, comunicação pessoal). Outras enfermidades como intoxicação por Aspergilus clavatus (Loretti et al 2003b), Ipomoea asarifolia (Tokarnia et al. 2000), Phalaris angusta (Gava et al 1999, Sousa \& Irigoyen 1999), Claviceps paspali (Riet-Correa et al. 1983b, Tokarnia et al. 2000, Barros et al. 2006) são doenças que devem ser levadas em consideração no diagnóstico diferencial. A intoxicação por Solanum fastigiatum var fastigiatum é a principal doença a ser considerada para o diagnóstico diferencial no sul do Brasil. Os sinais clínicos e a lesão histológica são muito semelhantes às causadas pela intoxicação por $S$. carpinifolia, porém, clinicamente as crises convulsivas são comuns na intoxicação por $S$. fastigiatum (Barros et al. 1987, Riet-Correa et al. 1983a). Microscopicamente, a diferenciação pode ser feita utilizando-se a técnica de histoquímica com lectinas, através da qual a intoxicação por S. carpinifolia é caracterizada como uma alfa-manosidose (Driemeier et al 2000, Loretti et al. 2003a) e a intoxicação por S. fastigiatum como uma glicolipidose (Paulovich et al. 2002).

Sida carpinifolia é tóxica para bovinos, quando ingerida em quantidades superiores a $10 \mathrm{~g} / \mathrm{kg}$, por um período de 120 dias produzindo alterações clínicas leves. Quando ingerida em doses de 30 e 40 $/ \mathrm{kg}$ por um período de 150 dias produz sinais nervosos moderados a severos. As principais lesões histológicas produzidas por S. carpinifolia em bovinos são: tumefação, vacuolização e necrose neuronal principalmente nos neurônios de Purkinje e vacuolização das células foliculares da tireóide e células acinares do pâncreas. $O$ consumo de S. carpinifolia por tempo prolongado produz doença de depósito lisossomal em bovinos.

Agradecimentos.- Ao Professor Severo Sales de Barros, Universidade Federal de Pelotas, pela realização da microscopia eletrônica e à Universidade do Estado de Santa Catarina, pelo suporte financeiro. 


\section{REFERÊNCIAS}

Armesto R.R., Reppeto A.E., Ortega H.H., Peralta C.J., Pensiero J.F., P.K. \& Salvetti N.R. 2004. Intoxicacion en cabras por ingestion de Ipomoea hieronymi var. calchaquina en la provincia de Catamarca, Argentina. Vet. Argent. 21(205):232-241.

Armién A.G., Tokarnia C.H., Peixoto P.V. \& Frese K. 2007. Spontaneous and experimental glycoprotein storage disease of goats induced by Ipomoea carnea subsp. fistulosa (Convolvulaceae). Vet. Pathol. 44:170-184.

Balogh K.K.I.M., Dimande A.P., Van der Lugth J.J., Molyneux R.J., Naudé T.W. \& Welman W.G. 1999. A lysossomal storage disease induced by Ipomoea carnea in goats in Mozambique. J. Vet. Diagn. Invest. 11:266-273.

Barbosa R.C., Riet-Correa F., Medeiros R.T.M., Lima E.F., Barros S.S., Gimeno E.R., Molyneux R.J. \& Gardner D.R. 2006. Intoxication by Ipomoea sericophylla and Ipomoea riedelii in goats in the state of Paraíba, northestern Brazil. Toxicon 47:371-379.

Barros S.S., Riet-Correa F., Andujar M.B., Barros C.S.L., Méndez M.C. \& Schild A.L. 1987. Solanum fastigiatum var. fastigiatum and Solanum sp. poisoning in cattle: ultrastructural changes in the cerebellum. Pesq. Vet. Bras. 7(1):1-5.

Barros C.S.L. Driemeier D., Dutra I.S., \& Lemos R.A.A. 2006. Doenças do Sistema Nervoso de Bovinos no Brasil. Vallée, Montes Claros, MG. 207p.

Burditt L.J., Chotai K., Hirani S., Nugent P.G., Winchester B.G. \& Blakemore W.F. 1980. Biochemical studies on a case of feline mannosidosis. Biochem. J. 189:467-473.

Chotai K., Jennings C., Winchester B. \& Dorling P. 1983. The uptake of swainsonine, a specific inhibitor of $\alpha$-D-mannosidase, into normal human fibroblasts in culture. J. Cell. Biochem. 21:107-117.

Colodel E.M. 2005. Intoxicação por Sida carpinifolia (Malvaceae) em caprinos. Tese de Doutorado, Univ. Fed. Rio Grande do Sul, Porto Alegre, RS. 88p.

Colodel E.M. 2006. Comunicação pessoal (Faculdade de Agronomia e Medicina Veterinária, UFMT, Cuiabá).

Colodel E.M., Driemeier D., Loretti A.P., Gimeno E.J., Traverso S.D., Seitz A.L. \& Zlotowski P. 2002a. Aspectos clínicos e patológicos da intoxicação por Sida carpinifolia (Malvaceae) em caprinos no Rio Grande do Sul. Pesq. Vet. Bras. 22(2):51-57.

Colodel E.M., Gardner D.R., Zlotowski P. \& Driemeier D. 2002b. Identification of swainsonine as a glycoside inhibitor responsible for Sida carpinifolia poisoning. Vet. Hum. Toxicol. 44(3):177-178.

Damir H.A., Adam S. \& Tartour G. 1987. The effects of Ipomoea carnea on goats and sheep. Vet. Hum. Toxicol. 29(4):316-319.

Dantas A.F.M., Riet-Correa F., Gardner D.R., Medeiros R.M.T., Barros S.S., Anjos B.L. \& Lucena R.B. 2006. Swainsonine induced lysosomal storage disease in goats caused by the ingestion of Turbina cordata in northeastern Brazil. Toxicon 49(1):111-116.

Dorling R., Huxtable C.R. \& Vogel P. 1978. Lysosomal storage in Swainsona spp. toxicosis: An induced mannosidosis. Neuropathol. Appl. Neurobiol. 4:285-298.

Dorling R., Huxtable C.R. \& Colegate S.M. 1980. Inhibition of lysossomal á-mannosidase by swainsonine, an indolizidine alkaloid isolated from Swainsona cadescens. Biochem. J. 191:649-651.

Driemeier D., Colodel E.M., Gimeno E.J. \& Barros S.S. 2000. Lysosomal storage disease caused by Sida carpinifolia in goats. Vet. Pathol. 37(2):153-159.

Elbein A., Solf R., Dorling P.R. \& Vosbeck K. 1981. Swainsonine: An inhibitor of glycoprotein processing. Proc. Natl Acad. Sci. USA 78(12):7393-7397.

Fuhrmann U., Bause E. \& Ploegh H. 1985. Inhibitors of oligosaccharide processing. Biochim Biophys Acta 825:95-110.

Furlan F.H. 2007. Intoxicação espontânea e experimental por Sida carpinifolia (Malvaceae) em bovinos. Dissertação de Mestrado, Universidade do Estado de Santa Catarina, Lajes. 44p.
Furlan F.H., Lucioli J., Medeiros A. \& Gava A. 2005. Sida carpinifolia em bovinos: relato de caso. Arq. Bras. Med. Vet. Zootec. 57(Supl.1):9. (Resumo)

Gava A., Sousa R.S., de Deus M.S., Pilati C., Cristani J., Mori A. \& Neves D.S. 1999. Phalaris angusta (Gramineae) como causa de enfermidade neurológica em bovinos no estado de Santa Catarina. Pesq. Vet. Bras.19(1):35-38.

Godoy G.S., Castro Neto A., Momo C., Dune A.C.C., Ávila L.G., Alessi A.C., Marques L.C. \& Castro M.B. 2005. Intoxicação natural por Sida carpinifolia (Malvaceae) em caprinos no estado de São Paulo. Arq. Bras. Med. Vet. Zootec. 57(Supl.1):25.

James L.F., Hartley W.J. \& Van Kampen K.R. 1981. Syndromes of Astragalus poisoning in livestock. J. Am. Vet. Med. Assoc. 178(2):146150.

Jolly R.D. \& Thompson K.G. 1978. The pathology of bovine mannosidosis. Vet. Pathol. 15:141-152.

Laws L. \& Anson R.B. 1968. Neuronopathy in sheep fed Swainsona luteola and Swainsona galegifolia. Aust. Vet. J. 44:447-452.

Lorenzi H. 2000. Plantas Daninhas do Brasil: terrestres, aquáticas, parasitas, tóxicas e medicinais. $5^{\underline{a}}$ ed. Plantarum, Nova Odessa, SP, p.471-478.

Loretti A.P., Colodel E.M., Gimeno E.J. \& Driemeier D. 2003a. Lysossomal storage disease in Sida carpinifolia toxicosis: an induced mannosidosis in horses. Equine Vet. J. 35:434-438.

Loretti A.P., Colodel E.M., Driemeier D., Correa A.M., Bangel J.J.Jr \& Ferreiro L. 2003b. Neurological disorder in dairy cattle associated with consumption of beer residues contamined with Aspergillus clavatus. J. Vet. Diagn. Invest.15:123-132.

Maenhout T., Kint J.A., Dacremont G., Ducatelle R., Leroy J.G. \& Hoorens J.K. 1988. Mannosidosis in a litter of Persian cats. Vet. Rec. 122(15):351-354.

Muntz F.H.A., Bonning L.E. \& Carey W.F. 1999. $\alpha$-Mannosidosis in a Guinea pig. Lab Anim. Sci. 49(4):424-426.

Ockerman P.A. 1967. Deficiency of beta-galactosidase and alphamannosidase: primary enzyme defects in gargolism and a new generalized disease? Acta Paediatr. Scand. 177:35-36.

Paulovich F.B., Portiansky E.L., Gimeno E.J., Schild A.L., Méndez M.D. \& Riet-Correa F. 2002. Lectin histochemical study of lipopigments present in the cerebellum of Solanum fastigiatum var. fastigiatum intoxicated cattle. J. Vet. Med. A, Physiol. Pathol. Clin. Med. 49:473477.

Pienaar J.G., Kellerman T.S., Basson P.A., Jenkins W.L. \& Vahrmeijer J. 1976. Maldronksiekte in cattle: a neuronopathy caused by Solanum kwebense N.E.Br. Onderstepoort J. Vet. Res. 43(2):67-64.

Riet-Correa F., Méndes M.C., Schild A.L., Summers B.A. \& Oliveira J.A. 1983a. Intoxication by Solanum fastigiatum var. Fastigiatum as a cause of cerebellar degeneration in cattle. Cornell Vet. 73:240-256.

Riet-Correa F., Schild A.L., Méndez M.C., Tavares A.S. \& Rodrigues J.O. 1983b. Intoxicação por Claviceps paspali em bovinos no Rio Grande do Sul. Pesq. Vet. Bras. 3(2):59-65.

Seitz A.L., Colodel E.M., Barros S.S. \& Driemeier D. 2005. Intoxicação experimental por Sida carpinifolia (Malvaceae) em ovinos. Pesq. Vet. Bras. 25(1):15-20.

Sousa S.S. \& Irigoyen L.F. 1999. Intoxicação experimental por Phalaris angusta (Gramineae) em bovinos. Pesq. Vet. Bras. 19(3/4):116-122.

Summers B.A., Cummings J.F. \& Lahunta A. 1994. Degenerative diseases of the central nervous system: metabolic and circulatory disorders, p.208-349. In: St Louis, Missouri. 527p.

Tokarnia C.H., Döbereiner J. \& Peixoto P.V. 2000. Plantas Tóxicas do Brasil. Editora Helianthus, Rio de Janeiro. 310 p.

Tulsiani D.R.P., Harris T.M. \& Touster O. 1982. Swainsonine inhibits the biosynthesis of complex glycoproteins by inhibition of Golgi mannosidase II. Biol. Chem. 257(14):7936-7939.

Whitten J.H. \& Walker D. 1957. Neuronopathy and pseudolipidosis in Aberdeen Angus calves. J. Pathol. Bacteriol. 74:281-288. 